\title{
Impaired Adrenergic-Mediated Plasticity of Prefrontal Cortical Glutamate Synapses in Rats with Developmental Disruption of the Ventral Hippocampus
}

\author{
Sanjeev K Bhardwaj', Yiu Chung Tse', Richard Ryan', Tak Pan Wong' and Lalit K Srivastava*,' \\ 'Douglas Mental Health University Institute, Department of Psychiatry, McGill University, Montreal, QC, Canada
}

\begin{abstract}
Neonatal ventral hippocampus $(\mathrm{nVH})$ lesion in rats is a useful model to study developmental origins of adult cognitive deficits and certain features of schizophrenia. $\mathrm{nVH}$ lesion-induced reorganization of excitatory and inhibitory neurotransmissions within prefrontal cortical (PFC) circuits is widely believed to be responsible for many of the behavioral abnormalities in these animals. Here we provide evidence that development of an aberrant medial PFC (mPFC) $\alpha-\mid$ adrenergic receptor $(\alpha-\mid$ AR) function following neonatal lesion markedly affects glutamatergic synaptic plasticity within PFC microcircuits and contributes to PFC-related behavior abnormalities. Using whole-cell patch-clamp recording, we report that norepinephrine-induced $\alpha$-IAR-dependent long-term depression (LTD) in a subset of corticocortical glutamatergic inputs is strikingly diminished in mPFC slices from nVH-lesioned rats. The LTD impairment occurs in conjunction with completely blunted $\alpha$-IAR signaling through extracellular signal-regulated kinase I/2. These $\alpha$-IAR abnormalities have functional significance in a mPFC-related function, that is, extinction of conditioned fear memory. Post-pubertal animals with $\mathrm{nVH}$ lesion show significant resistance to extinction of fear by repeated presentations of the conditioned tone stimulus. mPFC infusion of an $\alpha$-IAR antagonist (benoxathian) or LTD blocking peptide (Tat-GluR2 3 ) impaired fear extinction in sham controls, but had no significant effect in the lesioned animals. The data suggest that impaired $\alpha$-I adrenergic regulation of cortical glutamatergic synaptic plasticity may be an important mechanism in cognitive dysfunctions reported in neurodevelopmental psychiatric disorders.

Neuropsychopharmacology (2014) 39, 2963-2973; doi:I0.1038/npp.20I4.142; published online 9 July 2014
\end{abstract}

\section{INTRODUCTION}

Neonatal ventral hippocampus (nVH) lesion induced by bilateral injection of the excitotoxin ibotenic acid in postnatal day 7 (PD7) rats has repeatedly been shown to result in post-pubertal abnormalities in cognitive, social, motivational, and motor behaviors (Marcotte et al, 2001; Tseng et al, 2009). Striking resemblance of the nature and temporal course of these behaviors to schizophrenia led to the suggestion that $\mathrm{nVH}$-lesioned animals serve as a model to test the neurodevelopmental hypothesis of schizophrenia. Converging evidence suggest that the neonatal lesions significantly compromise the development and functions of medial prefrontal cortex (mPFC; O'Donnell et al, 2002; Flores et al, 2005; Ryan et al, 2013), a brain region that receives direct excitatory projections from the $\mathrm{VH}$ (Carr and Sesack, 1996; Thierry et al, 2000). For example, we and other investigators have shown that $\mathrm{nVH}$ lesion leads to decrease in dendritic spines of pyramidal neurons (Flores et al, 2005;

*Correspondence: Dr LK Srivastava, Douglas Mental Health University Institute, Department of Psychiatry, McGill University, Room E2214 Perry Pavilion, 6875 LaSalle Boulevard, Montreal, QC, Canada H4H |R3, Tel: + $51476 \mid$ 6|3|, Fax: + | 514602 2263,

E-mail: lalit.srivastava@mcgill.ca

Received 21 February 2014; revised 3 June 2014; accepted 5 June 2014; accepted article preview online II June 2014
Marquis et al, 2008; Ryan et al, 2013), changes in the functional properties of glutamatergic and GABAergic synaptic inputs (Ryan et al, 2013), and altered regulation of pyramidal and putative interneurons in the PFC (O'Donnell et al, 2002; Tseng et al, 2008; Gruber et al, 2010). Aberrations in PFC functions, while considered to be key mechanisms in schizophrenia, are shared by many behavioral disorders (Volk and Lewis, 2010; Gamo and Arnsten, 2011); accordingly, it is being recognized that $\mathrm{nVH}$ lesion offers a unique paradigm to study mechanisms of PFC dysfunctions arising from a developmentally compromised brain, without regard to psychiatric diagnosis.

Work in our laboratory has shown that $\mathrm{nVH}$ lesion induces alterations in adult PFC $\alpha-1$ adrenergic receptor $(\alpha-$ $1 \mathrm{AR}$ ) expression and function, with no significant change in $\alpha$-2AR (Bhardwaj et al, 2004; Kamath et al, 2008; Al-Khairi et al, 2009). We have observed a reduced activation of protein kinase C (PKC) by $\alpha-1 \mathrm{AR}$ agonists in the mPFC of nVH-lesioned animals (Al-Khairi et al, 2009). Considerable evidence supports a role of noradrenergic system in the modulation of PFC-dependent attentional and cognitive functions (Aston-Jones et al, 2000; Berridge and Waterhouse, 2003; Ramos and Arnsten, 2007). Findings suggest that the plasticity of glutamate synapses in PFC could be an important mechanism by which adrenergic inputs regulate PFC activity and function. For example, 
norepinephrine (NE) acting on $\alpha-1$ AR produces a longterm depression (LTD) of AMPA receptor-mediated excitatory postsynaptic responses recorded from neurons in the mPFC (Marzo et al, 2010). LTD has been associated with PFC-related cognitive functions, such as behavioral flexibility (Nicholls et al, 2008).

Here we worked on the hypothesis that altered $\operatorname{mPFC} \alpha$ $1 \mathrm{AR}$ plasticity may mediate some of the cognitive abnormalities in the $\mathrm{nVH}$-lesioned rats by disrupting PFC synaptic plasticity. We focused on fear memory extinction as a paradigm to assess potential cognitive correlate of abnormal $\alpha$-1AR signaling, as this behavior is associated with adrenergic transmission within the mPFC (Hugues et al, 2007; Mueller et al, 2008; Do-Monte et al, 2010). We report that $\alpha$-1AR signaling through extracellular signal-regulated kinase $1 / 2($ ERK1/2) and $\alpha$-1AR-mediated LTD are markedly disrupted in the mPFC of nVH-lesioned rats. We also find that the $\alpha-1 \mathrm{AR}$ abnormality and LTD deficits may be related to abnormal extinction of conditioned fear displayed by the lesioned animals.

\section{MATERIALS AND METHODS}

\section{nVH Lesion}

Animal care and surgical procedures were according to guidelines of the Canadian Council of Animal Care and were approved by the McGill University Animal Care Committee. Timed pregnant Sprague-Dawley rats were obtained from Charles River Canada, and gave birth in our animal facility. NVH lesion was performed on PD7 male pups according to our previously described procedure (Flores et al, 1996; Ryan et al, 2013). Pups were anesthetized by hypothermia by covering in crushed ice for $18-20 \mathrm{~min}$, and secured on a modified platform fixed to Kopf stereotaxic apparatus. The 'lesion' group received bilateral VH infusions of $0.3 \mu \mathrm{l}$ ibotenic acid (Sigma; $10 \mu \mathrm{g} / \mu \mathrm{l}$ in $0.1 \mathrm{M}$ PBS) over a period of $2 \mathrm{~min}$, whereas the 'sham' group received the same volume of PBS (coordinates: AP $-3.0 \mathrm{~mm}$ from bregma, $\mathrm{ML} \pm 3.5 \mathrm{~mm}$ from midline, and DV $-5.0 \mathrm{~mm}$ from dura). After surgery, pups were placed on a heating pad until full recovery and returned to their respective mothers. After weaning (PD25), they were pair-housed (a sham and a lesioned per cage).

\section{Effect of Adrenergic Drugs on ERK1/2 Expression}

PFC coronal slices ( $200 \mu \mathrm{m}, 2.2-3.7 \mathrm{~mm}$ anterior to bregma) from PD60 animals were obtained on a Leica vibratome in chilled carbogenated $\left(95 \% \mathrm{O}_{2} / 5 \% \mathrm{CO}_{2}\right)$ artificial cerebrospinal fluid (ACSF; (in mM): $\mathrm{NaCl} 125, \mathrm{KCl} 2.5, \mathrm{NaHCO}_{3} 26$, $\mathrm{NaH}_{2} \mathrm{PO}_{4} 1.25, \mathrm{MgCl}_{2} 1, \mathrm{CaCl}_{2}$ 2, D-glucose 25, and $0.1 \%$ protease inhibitor cocktail (Sigma, cat. no. P-8340), pH 7.35 and osmolarity 310-320). Separate slices were incubated with either ACSF, or $\alpha$-1AR agonist phenylephrine (PE; $20 \mu \mathrm{M}$, Sigma) or PE $+\alpha-1 \mathrm{AR}$ antagonist prazosin $(20 \mu \mathrm{M}$; Sigma) for $10 \mathrm{~min}$ at room temperature. The area corresponding to the prelimbic (PL) and infralimbic (IL) mPFC was rapidly dissected and homogenized in buffer containing protease and phosphorylation inhibitors $(0.2 \mathrm{mM}$ PMSF, $1 \mathrm{mM}$ leupeptin, $1 \mathrm{mM}$ pepstatin, and $0.2 \mathrm{mM}$ sodium orthovanadate, $\mathrm{pH}$ 7.4). Western blotting was done as described previously (Al-Khairi et al, 2009). The blotted membranes were incubated with anti-phospho-ERK1/2 (p-ERK1/2) antibody $(1: 1000$, rabbit polyclonal, Cell Signaling, MA), followed by anti-rabbit IgG: horseradish peroxidase secondary antibody. The blots were developed using chemiluminescence system (PerkinElmer). After exposure to X-ray film, the blot was stripped and reprobed with a polyclonal antibody against total-ERK1/2 (t-ERK1/2; $1: 2500$, Cell Signaling). The membranes were re-stripped and probed using anti-tubulin antibody (1:5000, Sigma). Relative optical densities (ROD) of bands were analyzed on image analysis system (MCID-4, Imaging Research). ROD of p-ERK was normalized with t-ERK, and ROD of t-ERK was normalized with tubulin. The data were analyzed separately using two-way analysis of variance (ANOVA) with lesion and drug treatment as independent variables, followed by post hoc Tukey's test with $p$ set at 0.05 .

\section{Electrophysiological Recording}

Coronal $400 \mu \mathrm{m}$ PFC slices (PD42-57) were obtained as above and recovered at $32^{\circ} \mathrm{C}$ for $1 \mathrm{~h}$ in carbogenated ACSF. Slices were transferred to a submerged-type recording chamber and perfused with ACSF at a flow rate of $1.5 \mathrm{ml} / \mathrm{min}$ at room temperature. The recordings were done essentially as described by us previously (Bagot et al, 2012). Inhibitory synaptic function was reduced by the GABA-A receptor antagonist bicuculline $(1 \mu \mathrm{M}$, Sigma) in all recordings. Higher concentration of bicuculline was not used to avoid epileptiform discharges.

Whole-cell recording of excitatory postsynaptic potential (EPSP) was performed on layer $\mathrm{V}$ pyramidal neurons as previously described (Ryan et al, 2013). In brief, patch pipettes were pulled from borosilicate glass capillaries and filled with intracellular solution ( $\mathrm{pH} 7.25,280-290 \mathrm{mOsm}$ ) composed of (in $\mathrm{mM}$ ): $120 \mathrm{mM}$ K-gluconate, $17.5 \mathrm{KCl}$, 10 HEPES, $2 \mathrm{MgCl}_{2}, 0.5$ ethylene glycol tetraacetic acid, 4 ATP, and 5 QX-314 (pH 7.2). After breakthrough, cortical neurons were injected with several 200-ms long hyperpolarizing pulses to estimate the input resistance (179.3 \pm $15.7 \mathrm{M} \Omega$ ). $\mathrm{EPSP}_{\text {superficial }}$ and $\mathrm{EPSP}_{\text {deep }}$ were evoked by stimulating the superficial (layer I/II) and deep cortical layers (layer VI) via constant current pulses $(0.08 \mathrm{~ms})$ delivered through tungsten bipolar electrodes. EPSP $_{\text {superficial }}$ corresponds to excitatory inputs from pyramidal neurons in layer II/III pyramidal neurons, which relay information from layer VI neurons that received thalamocortical synaptic inputs, while EPSP ${ }_{\text {deep }}$ are mediated by collaterals between deep layer pyramidal neurons (Thomson and Deuchars, 1997). NE (20 $\mu$ M, Sigma) was added into the perfusing solution to induce LTD of EPSP for $10 \mathrm{~min}$. In experiments when two independent pathways were sequentially stimulated from superficial and deep cortical layers, the inter-stimulation intervals were set to be $700 \mathrm{~ms}$. Access resistance of the whole-cell recording was monitored continuously so that only recordings with low $(<15 \mathrm{M} \Omega)$ and stable access resistance $(<20 \%$ change) were kept for analysis.

\section{Fear Conditioning and Extinction}

PD60 sham and lesioned animals were used in the standard paradigm of fear conditioning essentially as described 
previously (Bhardwaj et al, 2009). Two minutes after placement in the boxes (Kinder Scientific, CA), the animals received four pairings of tone and footshock with a variable inter-trial interval (ITI) averaging $120 \mathrm{~s}$. The tone $(85 \mathrm{~dB})$ had duration of $30 \mathrm{~s}$; during the last second of the tone, a footshock ( $0.5 \mathrm{~mA}, 1 \mathrm{~s}$ duration) was delivered. Contextual fear memory was tested the next day in the same chamber without any footshock or tone. On day 3, auditory cued fear was determined in a novel box. After $3 \mathrm{~min}$ of habituation, animals were exposed to $3 \mathrm{~min}$ of continuous auditory tone of $85 \mathrm{~dB}$. The behavior of animals was videotaped and analyzed for the proportion of time spent freezing, in $5 \mathrm{~s}$ bin, by a person blind to experimental status. Freezing was defined as a lack of body movement, including head movement, and not in resting position.

Extinction of fear memory was assessed in a new cohort of rats essentially as described by Mueller et al (2008). Twenty four hours after tone-shock conditioning, extinction learning was evaluated in the conditioning box. After 2 min acclimatization, animals were exposed to a series of 14 tones (85 dB, $30 \mathrm{~s}$ duration) with a variable ITI (90-180 s). Freezing behavior was analyzed as above. On day 3 , recall (retrieval) of extinction memory was similarly evaluated by six presentations of the tone. The data is presented as block of two trials (averaged) during extinction learning and extinction recall.

\section{MPFC Microinfusion of $\alpha$-1AR Antagonist Benoxathian and Tat-GluR2 3 Y Peptide}

A cohort of animals (PD50-60) were anesthetized with isoflurane and implanted with a bilateral 26-gauge stainlesssteel guide cannula (Plastics One) aimed at IL PFC region $(\mathrm{AP}+2.9, \mathrm{ML} \pm 0.75$, and $\mathrm{DL}-4.1$; Paxinos and Watson, 2007). After 7 days, animals were fear conditioned as described above. A day later, animals were microinjected bilaterally with a water-soluble $\alpha-1 \mathrm{AR}$ antagonist benoxathian (Sigma) $(10 \mathrm{nmol}$ in $0.3 \mu \mathrm{l} / \mathrm{side})$ or ACSF to create four groups of animals: sham-ACSF, sham-benoxathian, lesion-ACSF, and lesion-benoxathian. Thirty minutes later, fear extinction was assessed by giving 14 tone-alone trials as described in the previous section. Twenty four hours later, recall of fear was evaluated in the same animals. Another group of conditioned animals (sham and lesioned) were similarly microinjected with either Tat-GluR2 $2_{3 Y}$ peptide or scrambled peptide (15 pmol each; Sheldon Biotechnology, McGill). Fear extinction and recall were assessed as described above. Drug doses were selected based on previous reports indicating effective blockade of $\alpha-1 \mathrm{AR}$ in $\mathrm{mPFC}$ (Nicniocaill and Gratton, 2007) and AMPAR endocytosis (Brebner et al, 2005). Data were analyzed by two or threeway repeated measure ANOVA followed by post hoc Tukey's test. Student's $t$-test was used for the analysis of the contextual memory.

\section{Lesion and Cannula Verification}

After experiment, animals were killed, and 35- $\mu \mathrm{m}$ coronal sections at the level of the VH or mPFC were stained with $0.5 \%$ Cresyl Violet. The extent of hippocampal damage was ascertained using a light microscope and MCID system.

\section{RESULTS}

As reported earlier (Flores et al, 1996; Bhardwaj et al, 2004), $\mathrm{nVH}$-lesioned animals showed bilateral neuronal loss, retraction, and cavitations in the ventral half of the hippocampus including the CA1 (Supplementary Figure S1). Only animals showing bilateral neuronal loss and atrophy of the $\mathrm{VH}$ with no significant damage to dorsal hippocampus or adjacent nuclei were included in data analyses.

\section{Effect of $\mathrm{nVH}$ Lesion on ERK1/2 Activation in PFC Slices}

We previously reported on a blunted $\alpha-1$ activation of PKC in nVH-lesioned animals (Al-Khairi et al, 2009). Here we evaluated mPFC ERK1/2 activation by a specific $\alpha-1 \mathrm{AR}$ agonist PE $(20 \mu \mathrm{M})$ in sham and lesioned animals $(n=7$ each). Figure la show representative western blots of $\mathrm{p}-\mathrm{ERK} 1 / 2$ and $\mathrm{t}$-ERK1/2. Two-way ANOVA of p-ERK1/2 level (ratio of p-ERK1/2 to t-ERK1/2; Figure $1 b$ ) showed a significant lesion $\times$ drug interaction $\left(\mathrm{F}_{2,36}=4.73 ; p=0.015\right)$. Incubation with $\mathrm{PE}$ increased ERK1/2 phosphorylation by over 2.5 -fold $(p=0.001)$ in slices from sham animals, which was blocked by co-incubation with the antagonist prazosin. Notably, however, PE completely failed to increase p-ERK1/2 level in the lesioned animals, suggesting an uncoupling between $\alpha-1 \mathrm{AR}$ and ERK1/2 signaling. $\mathrm{NVH}$-lesioned animals without agonist application (ACSF group) although appear to have increased basal p-ERK1/2 level compared with sham-ACSF; however, this is not statistically significant $(p=0.14)$. Finally, t-ERK1/2 level (ratio of t-ERK1/2 vs $\alpha$-tubulin) was not significantly different between sham and lesioned groups $\left(\mathrm{F}_{2,36}=0.22\right.$; $p=0.80$ ) (Figure 1c).

\section{Impairment of $\alpha$-1AR-Induced LTD in the MPFC of nVH-Lesioned Rats}

NE acting on $\alpha$-1AR produces a LTD of AMPAR-mediated excitatory postsynaptic responses in the cerebral cortex (Kirkwood et al, 1999), hippocampus (Scheiderer et al, 2004), and PFC (Marzo et al, 2010), and this LTD is mediated by ERK $1 / 2$. Here, we tested if changes in $\alpha-1 \mathrm{AR}-$ mediated ERK1/2 activation in $\mathrm{nVH}$-lesioned rats could affect NE-related synaptic plasticity in the mPFC. Under current-clamp mode, EPSPs evoked by stimulating either

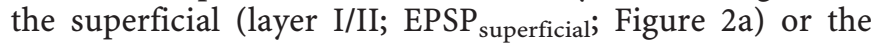
deep cortical layer (layer VI; EPSP ${ }_{\text {deep }}$ Figure 2b) were recorded from layer $\mathrm{V}$ pyramidal neurons in the $\mathrm{mPFC}$. In sham-operated rats $(n=4), \mathrm{NE}(20 \mu \mathrm{M}, 10 \mathrm{~min})$ induced LTD of EPSPs evoked by stimulating superficial cortical layers (changes in EPSP $_{\text {superficial }}$ at 30 min after NE application: $-33.2 \pm 9.4 \%$ vs baseline: $t(5)=3.53, p=0.017$, $n=6$ slice; Figure 2c). Moreover, NE failed to induce LTD of EPSPs evoked by stimulating deep cortical layers (changes in EPSP $_{\text {deep }}$ : $-6.2 \pm 12.5 \%$ vs baseline: $t(6)=$ $0.50, p=0.637, n=7$ slice; Figure 2d). Surprisingly, no

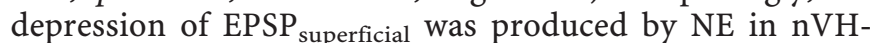
lesioned rats $(n=5)$. In fact, Student's $t$-test comparison revealed a trend of enhancement of EPSP superficial $_{\text {at }} 30 \mathrm{~min}$ after NE treatment $(27.3 \pm 11.7 \%$ vs baseline: $t(6)=2.34$, $p=0.057, n=7$ slices; Figure 2e). Similar to its effect on sham-operated control rats, NE did not affect EPSP $_{\text {deep }}$ in 

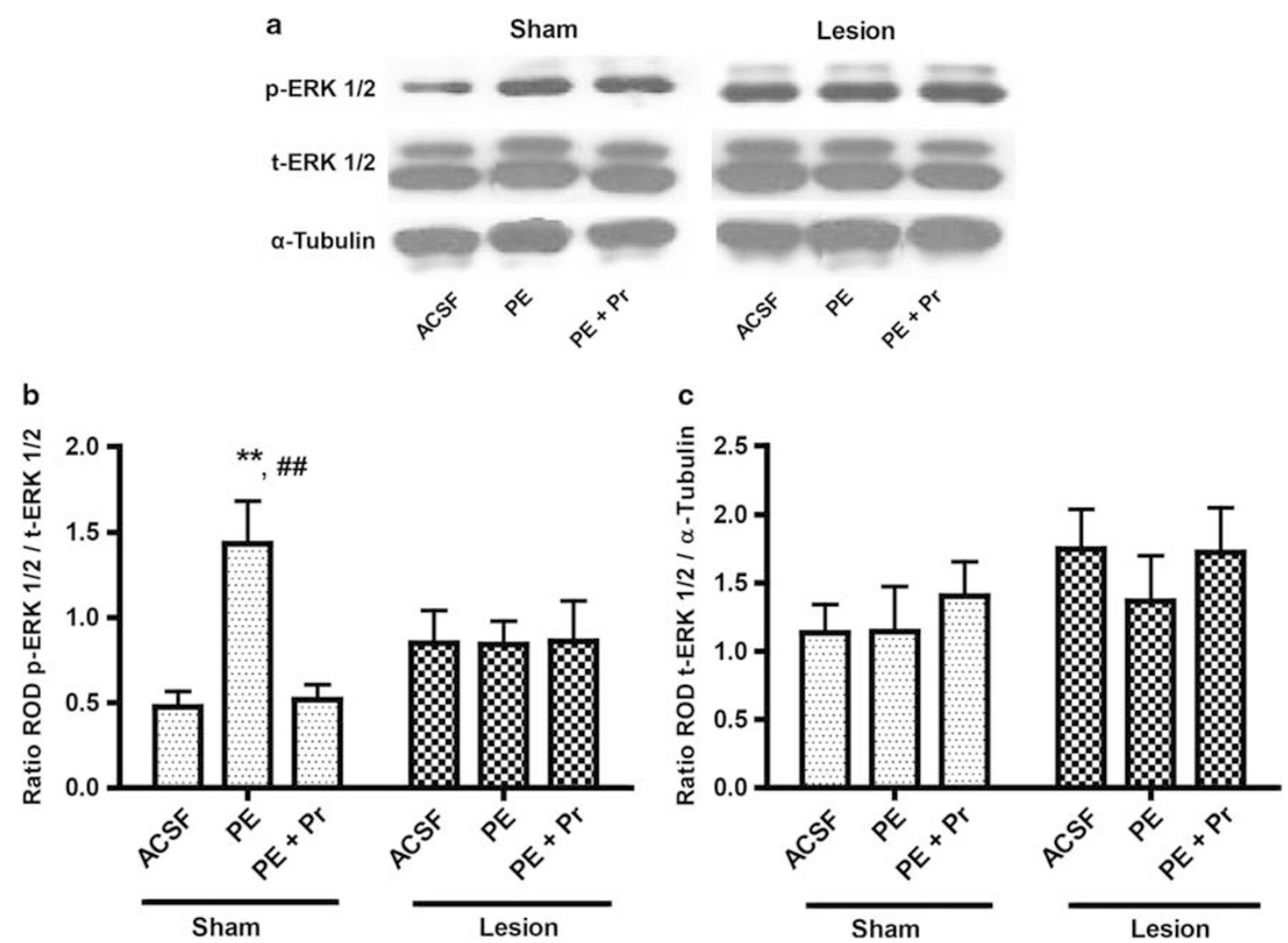

Figure I Effect of neonatal ventral hippocampus $(\mathrm{nVH})$ lesion on extracellular signal-regulated kinase I/2 (ERKI/2) activation in prefrontal cortex (PFC) slices. (a) Representative western blot signals using antibodies for (phospho) $\mathrm{p}$-ERKI/2, (total) t-ERKI/2 and $\alpha$-tubulin. (b and c) show mean \pm SEM ratio of relative optical density (ROD) of $\mathrm{p}$-ERKI/2 vs t-ERKI/2, as well as t-ERKI/2 vs tubulin. Incubation with $\alpha$ - IAR agonist phenylephrine (PE) stimulates $p$-ERKI/2 in the sham but not lesioned animals $(* * p=0.00 \mathrm{I})$. PE-induced $p$-ERKI/2 stimulation is $\alpha$ - IAR dependent as it is completely blocked by antagonist prazosin $\left(\mathrm{Pr} ;{ }^{\# \#} p=0.001\right.$, sham PE vs sham PE $\left.+\mathrm{Pr}\right)$.

nVH-lesioned rats $(-9.6 \pm 7.2 \%$ vs baseline: $t(5)=1.34$, $p=0.239, n=6$ slice; Figure 2f). Two-way ANOVA on the data of lesion and inputs (superficial $v s$ deep) on NE-LTD of EPSP and found significant interaction between inputs and lesion $(\mathrm{F}(1,19)=5.67 ; p=0.028)$. Post hoc Tukey's test revealed significant difference of the slope of EPSP between sham and nVH-lesioned rats $(p=0.012)$.

NE-LTD was abolished by an $\alpha-1$ AR antagonist prazosin (changes in $\mathrm{EPSP}_{\text {superficial }}$ at $30 \mathrm{~min}$ after $\mathrm{NE}$ application: $4.7 \pm 9.1 \%$ vs baseline: $t(3)=0.51, p=0.866, n=4$, two rats; Figure 2g), suggesting the involvement of $\alpha-1$ AR. AMPA receptor endocytosis is an important expression mechanisms for activity-dependent LTD in both the hippocampus and mPFC (Collingridge et al, 2010). In support of the requirement of AMPAR endocytosis for LTD in mPFC, it has been shown that an interfering peptide GluR2 $2_{3 \mathrm{Y}}$, which disrupts tyrosine phosphorylation of GluR2 subunit (Ahmadian et al, 2004), impairs LTD formation (Van den Oever et al, 2008). To examine whether NE-LTD expression is mediated by AMPAR endocytosis, we added the GluR2 $3 \mathrm{Y}$ peptide into intracellular solution $(100 \mathrm{ng} / \mathrm{ml})$, and found that NE failed to induce LTD (changes in $\mathrm{EPSP}_{\mathrm{V}}$ at $30 \mathrm{~min}$ after NE application: $2.2 \pm 10.2 \%$ vs baseline: $t(3)=0.21, p=0.845, n=4$, from four rats; Figure $2 \mathrm{~h}$ ).

\section{NVH Lesion Leads to Impaired Fear Extinction}

Two-way repeated measure ANOVA of conditioning data ( $n=7$ each group) showed no significant effect of lesion $\left(\mathrm{F}_{1,48}=0.55, p=0.47\right)$ or lesion $\times$ trial interaction $\left(\mathrm{F}_{4,48}=\right.$ $2.08, p=0.1$; Figure 3a). Student's $t$ - test of contextual fear memory showed no significant difference of the sham and lesioned animals $(p=0.70)$ (Figure $3 \mathrm{~b})$. Similarly, two-way ANOVA of auditory fear memory revealed no significant effect of lesion $\left(\mathrm{F}_{(1,11)}=0.73, p=0.41\right)$ or lesion $\times$ tone interaction $\left(\mathrm{F}_{(1,11)}=0.52, p=0.49\right.$; Figure $\left.3 \mathrm{c}\right)$.

Analysis of extinction data ( $n=7$ each) showed that $\mathrm{nVH}$ lesion causes a significant impairment in the extinction of conditioned fear memory. During extinction trials, sham animals showed reduction in freezing that decreased to $\sim 20 \%$ after 14 trials, whereas lesioned animals showed only $\sim 50 \%$ reduction at the end of the trials. Two-way ANOVA of extinction learning trials showed a significant effect of lesion $\left(\mathrm{F}_{(1,72)}=5.34, \quad p=0.04\right)$ and tone $\left(\mathrm{F}_{(6,72)}=5.76, p=0.0001\right)$ but no lesion $\times$ tone interaction $\left(\mathrm{F}_{(6,72)}=0.85, p=0.53\right.$; Figure $\left.3 \mathrm{~d}\right)$. Analysis of recall of fear memory $24 \mathrm{~h}$ after extinction also showed a significant main effect of lesion $\left(\mathrm{F}_{(1,24)}=10.24, p=0.008\right)$ but not tone trials $\left(\mathrm{F}_{(2,24)}=0.44, \quad p=0.064\right) \quad$ or lesion $\times$ tone interaction $\left(\mathrm{F}_{(2,24)}=1.76, p=0.193\right.$; Figure $\left.3 \mathrm{e}\right)$. 
Layer I

Stimulation

a
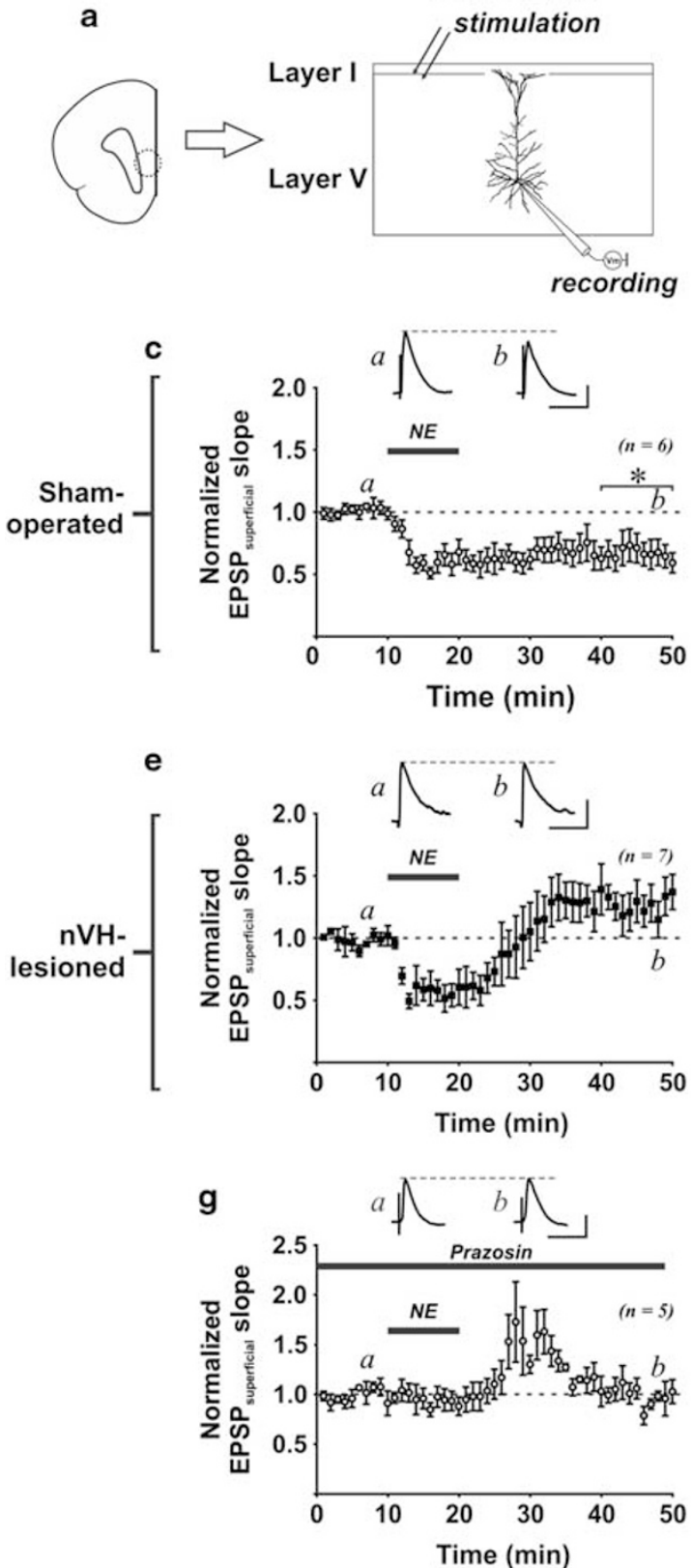

Layer VI

Stimulation

b
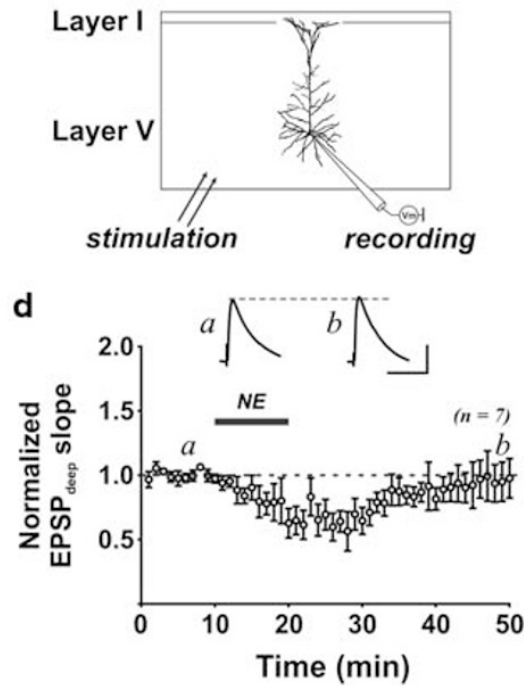

f
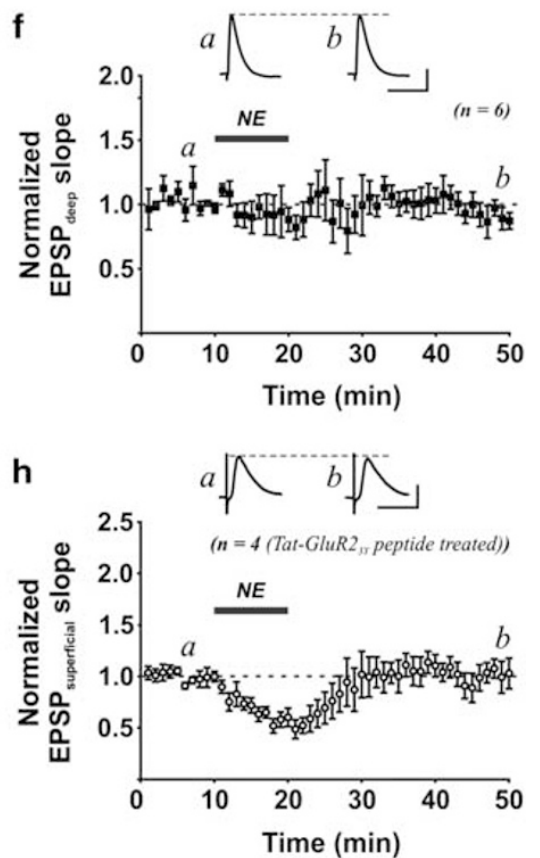

Figure 2 Norepinephrine (NE)-induced long-term depression (LTD) in the prefrontal cortex (PFC) is abolished by neonatal ventral hippocampus (nVH)lesion. (a) Left figure shows the infralimbic region of the PFC (dotted line circle) that was examined in this study. (a, b) The schematic diagrams depicting the placement of recording and stimulating electrodes. Whole-cell excitatory postsynaptic potentials (EPSPs) evoked by stimulating either the layer I/II $\left(\right.$ EPSP $\left._{\text {superficial }}\right)$ or layer $\mathrm{VI}$ cortical inputs $\left(E P S P_{\text {deep }}\right)$ were recorded from layer $V$ pyramidal neurons. (c) A brief NE treatment $(20 \mu M$, I 0 min) induced LTD of EPSP superficial in slices obtained from sham-operated rats. ${ }^{*} p=0.017$ vs baseline EPSP before NE application. (d) Note that similar NE treatment did not produce long-lasting change of EPSP deep. (e, f) NE failed to induce LTD of EPSP superficial $_{\text {and }}$ EPSP deep in slices obtained from $n V H$ lesion rats. (g) Using slices obtained from control rats, NE-LTD of EPSP superficial can be abolished by $\alpha$ - I adrenergic receptor antagonist prazosin (I0 $\mu M$ ). (h) A short Tat-GluR2 $3 Y$ peptide, which is known to inhibit the endocytosis of AMPA receptor, was delivered to layer $V$ pyramidal neurons recorded from slices of control rats through whole-cell recording. NE failed to induce LTD of EPSP superficial in peptide-treated neurons.

Blockade of $\alpha$-1AR in mPFC Impairs Fear Extinction in Sham Animals, but does not Exacerbate Extinction Deficit in Lesioned Animals

We investigated whether abnormality in mPFC $\alpha-1 \mathrm{AR}$ function could be related to extinction deficits of $\mathrm{nVH}$ animals by microinfusing $\alpha-1 \mathrm{AR}$ antagonist benoxathian
( $n=6-7$ each group; Figure 4a). Three-way ANOVA showed a significant effect of lesion $\left(\mathrm{F}_{(1,126)}=12.37, p=0.002\right)$ as well benoxathian $\times$ lesion interaction $\left(\mathrm{F}_{(1,126)}=10.92\right.$, $p=0.003)$. A two-way ANOVA comparing average \% freezing at the last block of two trials indicates that sham animals with benoxathian infusion, compared with ACSF infusion, show higher freezing, that is, resistance to 
a
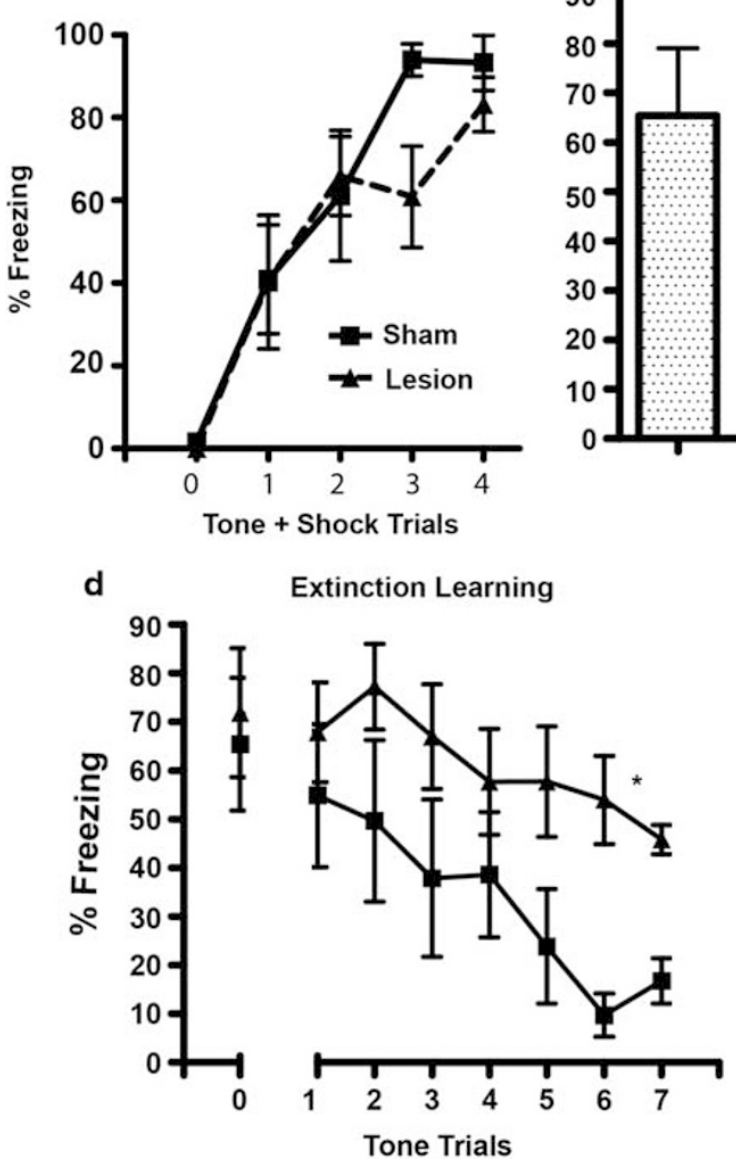

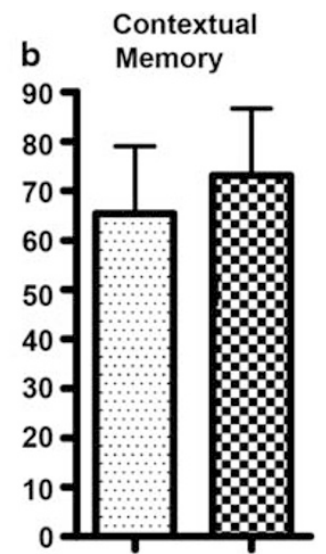

C

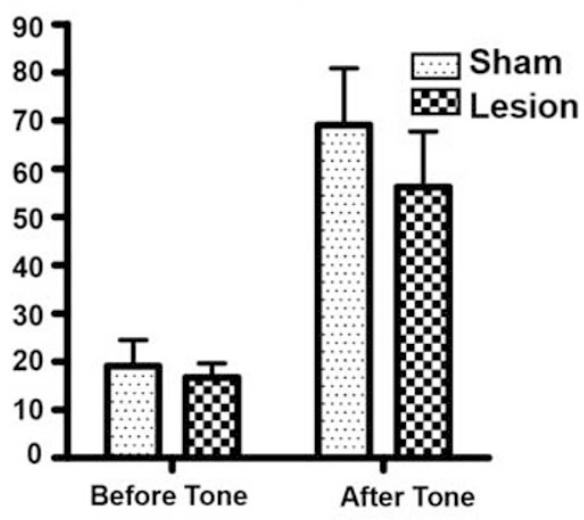

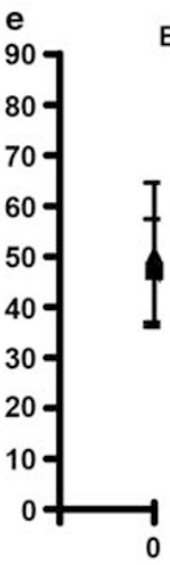

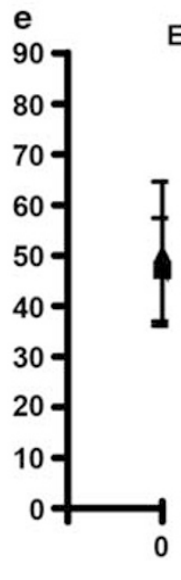

Extinction Recall

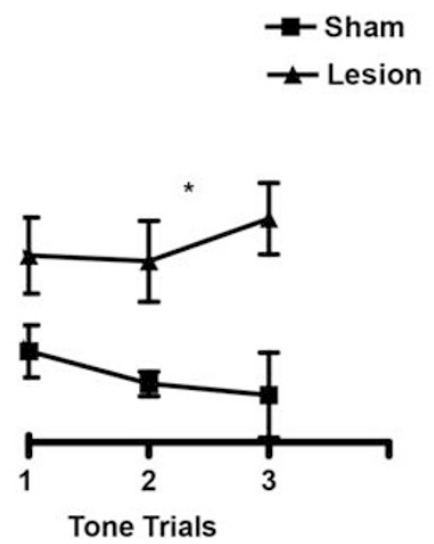

Figure 3 Fear memory and extinction in sham and neonatal ventral hippocampus ( $n V H)$-lesioned animals. (a) Mean ( \pm SEM) fear behavior (\% time freezing) during fear conditioning is not significantly different between sham and nVH-lesioned rats. (b) The two groups of rats also do not differ in contextual fear memory assessed by exposure to the conditioning context $24 \mathrm{~h}$ following fear conditioning. (c) Auditory fear memory by the presentation of conditioned stimulus (tone) $48 \mathrm{~h}$ following fear conditioning also did not differ in the sham and nVH-lesioned rats. (d) $\mathrm{nVH}$ lesion leads to impaired extinction of fear memory as lesioned animals show increased fear behavior compared with sham animals during presentation of repeated tone trials. (e) Lesioned animals show impaired recall of fear memory as assessed by tone presentation, a day after extinction learning trials. The extinction training and recall data are presented as pool of two-tone trials. *Two-way analysis of variance (ANOVA) of extinction training and recall showing significant effect of lesion ( $p=0.04$ and $p=0.008$, respectively).

extinction (lesion $\times$ drug interaction, $\mathrm{F}_{(1,21)}=4.40$, $p=0.043$; post hoc $p=0.002$; Figure $4 \mathrm{~b}$ ). The lesioned animals with ACSF infusion showed impaired extinction compared with sham-ACSF group $(p=0.004)$ as observed earlier (Figure 3d). However, $\alpha-1 \mathrm{AR}$ antagonist infusion had no further effect in lesioned animals. Taken together with our observations of abnormal $\alpha-1 \mathrm{AR}$ signaling and LTD, these data showing similar impairments of extinction in lesioned animals without drug and controls with mPFC $\alpha-1$ blockade indicate a relationship between dysfunctional $\alpha-1 \mathrm{AR}$ and impaired extinction after $\mathrm{nVH}$ lesion.

The effect of benoxathian infusion in sham and lesioned animals during recall of extinction memory parallels its effect seen during extinction learning (Figure $4 c$ and d). Three-way ANOVA showed a significant effects of lesion $\left(\mathrm{F}_{(1,42)}=23.71, p=0.001\right)$ and lesion $\times \operatorname{drug}\left(\mathrm{F}_{(1,42)}=7.36\right.$, $p=0.013$; Figure $4 \mathrm{c})$. A two-way ANOVA of $\%$ freezing during the last block of trial showed a significant lesion $x$ drug interaction $\left(\mathrm{F}_{(1,20)}=4.74, p=0.042\right)$. Sham-benox- athian animals freeze at higher levels at the end of recall session compared with sham-ACSF animals $(23.4 \%$ vs $11.1 \%$; Figure $4 \mathrm{~d}$ ), however, this change did not reach statistical significance. Lesioned-ACSF animals also show impaired recall memory compared with sham-ACSF group. However, as observed for extinction learning, benoxathian infusion had no significant effect in the lesioned animals.

\section{MPFC Blockade of AMPA Receptor Endocytosis}

Disrupts fear Extinction in Sham Animals, but has no Significant Effect in Lesioned Animals

We examined the effect of IL infusion of Tat-GluR2 $2_{3 Y}$ peptide given $30 \mathrm{~min}$ before extinction $(n=9-13)$. Threeway ANOVA of extinction trials showed a significant effect of lesion $\left(\mathrm{F}_{(1,222)}=7.25, p=0.01\right)$ and lesion $\times$ peptide interaction $\left(\mathrm{F}_{(1,222)}=6.54, p=0.014\right)$, but not of peptide alone $\left(\mathrm{F}_{(1,222)}=0.57, p=0.45\right.$; Figure $\left.5 \mathrm{a}\right)$. Comparing $\%$ freezing at the last block of trial indicates that sham animals 


\section{Extinction Learning}
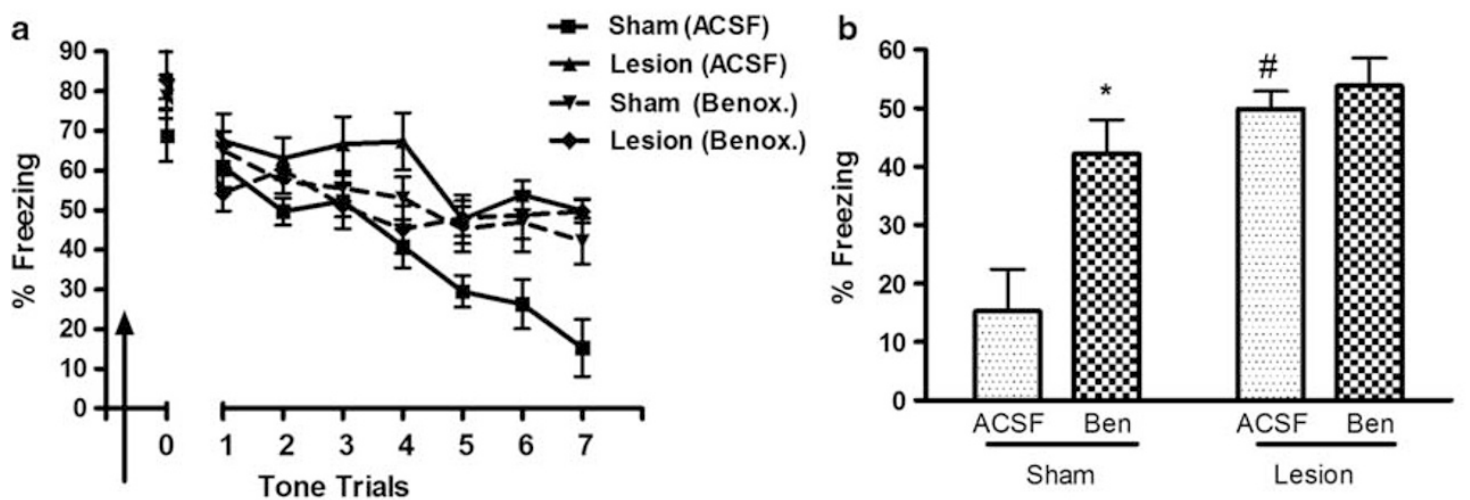

Extinction Recall
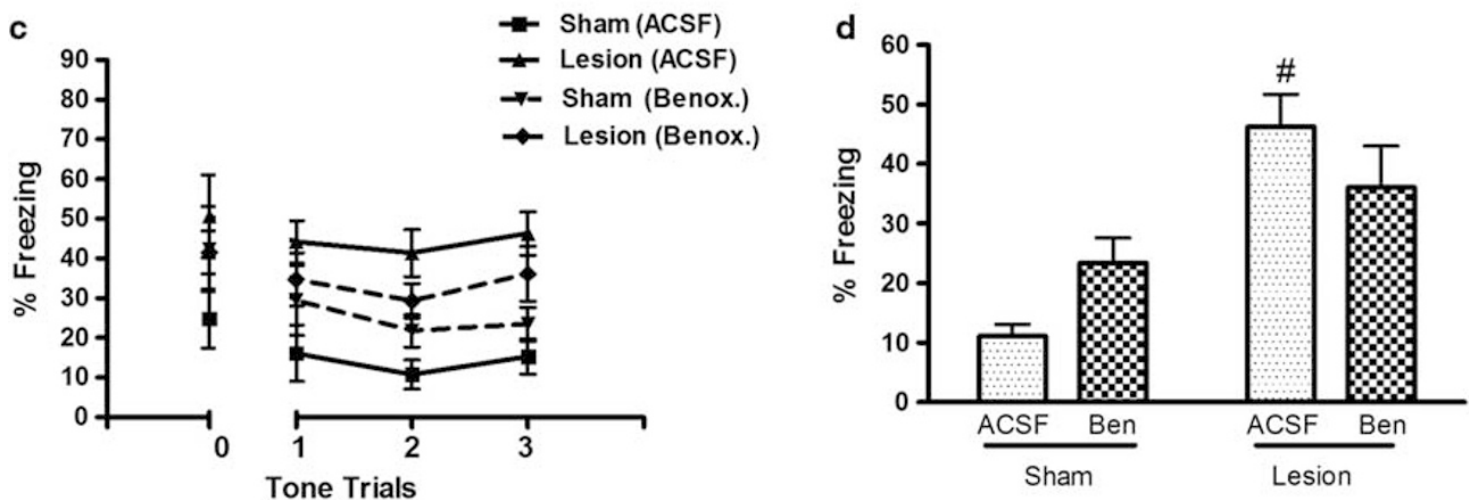

Figure 4 Effect of medial prefrontal cortex (mPFC) $\alpha$-I adrenergic blockade on extinction memory in sham and neonatal ventral hippocampus ( $\mathrm{nVH}$ )lesioned animals. (a) Extinction learning curve of rats infused with either artificial cerebrospinal fluid (ACSF) or benoxathian (Benox or Ben) bilaterally into infralimbic PFC, 30 min before the session (arrow sign). (b) Bar diagram of mean ( \pm SEM) freezing response at the last block of two trials in the four groups of animals. Sham animals with mPFC benoxathian infusion, compared with ACSF, show higher freezing indicating resistance to extinction learning. However, the $\alpha$-I adrenergic receptor $(\alpha-I A R)$ antagonist has no significant effect in $n V H$-lesioned animals, that is, do not exacerbate extinction deficit of lesioned animals (* $p=0.002$ and ${ }^{\#} p=0.004$ compared with sham-ACSF group. (c) Freezing responses of the animals during the extinction recall. (d) Mean \pm SEM of freezing response at the last block of two-tone trials during recall ( ${ }^{\#} p=0.0003$ compared with sham-ACSF).

with Tat-GluR2 $2_{3 Y}$ infusion, compared with scrambled peptide infusion, show significant disruption in extinction learning (lesion $\times$ peptide interaction: $F_{(1,37)}=11.00$, $p=0.002$; pair-wise post hoc $p=0.005)$. Lesion-scrambled peptide animals showed significantly higher freezing than sham-scrambled peptide group $(p<0.001)$; however, similar to the observations with benoxathian, Tat-GluR2 $2_{3 Y}$ peptide had no significant effect in the lesioned animals; (Figure 5b).

The effect of peptide in recall of extinction memory is also similar to its effect seen during extinction learning (Figure $5 \mathrm{c}$ and $\mathrm{d}$ ) in that a three-way ANOVA showed a significant main effect of lesion $\left(\mathrm{F}_{(1,74)}=11.99, p=0.001\right)$. However, no significant effect of Tat-peptide $\left(\mathrm{F}_{(1,74)}=0.78\right.$, $p=0.38$ ) or lesion $\times$ peptide interaction was observed on extinction recall $\left(\mathrm{F}_{(1,74)}=2.02, p=0.164\right.$; Figure $\left.5 \mathrm{c}\right)$. Analysis of last block of trials shows that scrambled peptide-infused nVH-lesioned animals showed impaired fear recall compared with scrambled peptide-infused sham animals $\left(\mathrm{F}_{(1,137)}=16.96, p=0.0002\right)$. However, Tat-peptide infusion in the sham or lesioned animals produced no significant effects on extinction recall (Figure 5d).

\section{DISCUSSION}

The principal finding of our study is that the lesion of $\mathrm{VH}$ at a developmentally critical age in rats leads to post-pubertal alterations in prefrontal $\alpha-1 \mathrm{AR}$-mediated signaling, synaptic plasticity and behavior. A key $\alpha$-1AR-mediated intracellular signaling mechanism, that is, ERK1/2 activation, is anomalous in the mPFC of lesioned animals. Incubation with a specific $\alpha-1 \mathrm{AR}$ agonist increased ERK1/2 phosphorylation in the control mPFC as expected; however, this activation was not observed in the lesioned animals. There was no significant change in the level of t-ERK1/2 in the lesioned group. Agonist activation of $\alpha 1-\mathrm{AR}$ leads to intracellular signaling cascade that includes, among others, PKC and ERK1/2 (Koshimizu et al, 2003). We have previously reported that PKC activation by $\alpha-1 \mathrm{AR}$ is also blunted in the prefrontal slices of nVH-lesioned animals (Al-Khairi et al, 2009). Thus, taken together, our data point to a severe dysregulation of cortical $\alpha-1 \mathrm{AR}$ function in the lesioned animals.

Based on the reported roles of $\alpha-1 \mathrm{AR}$ and ERK1/2 in PFC LTD (Marzo et al, 2010) and our recent observation of 

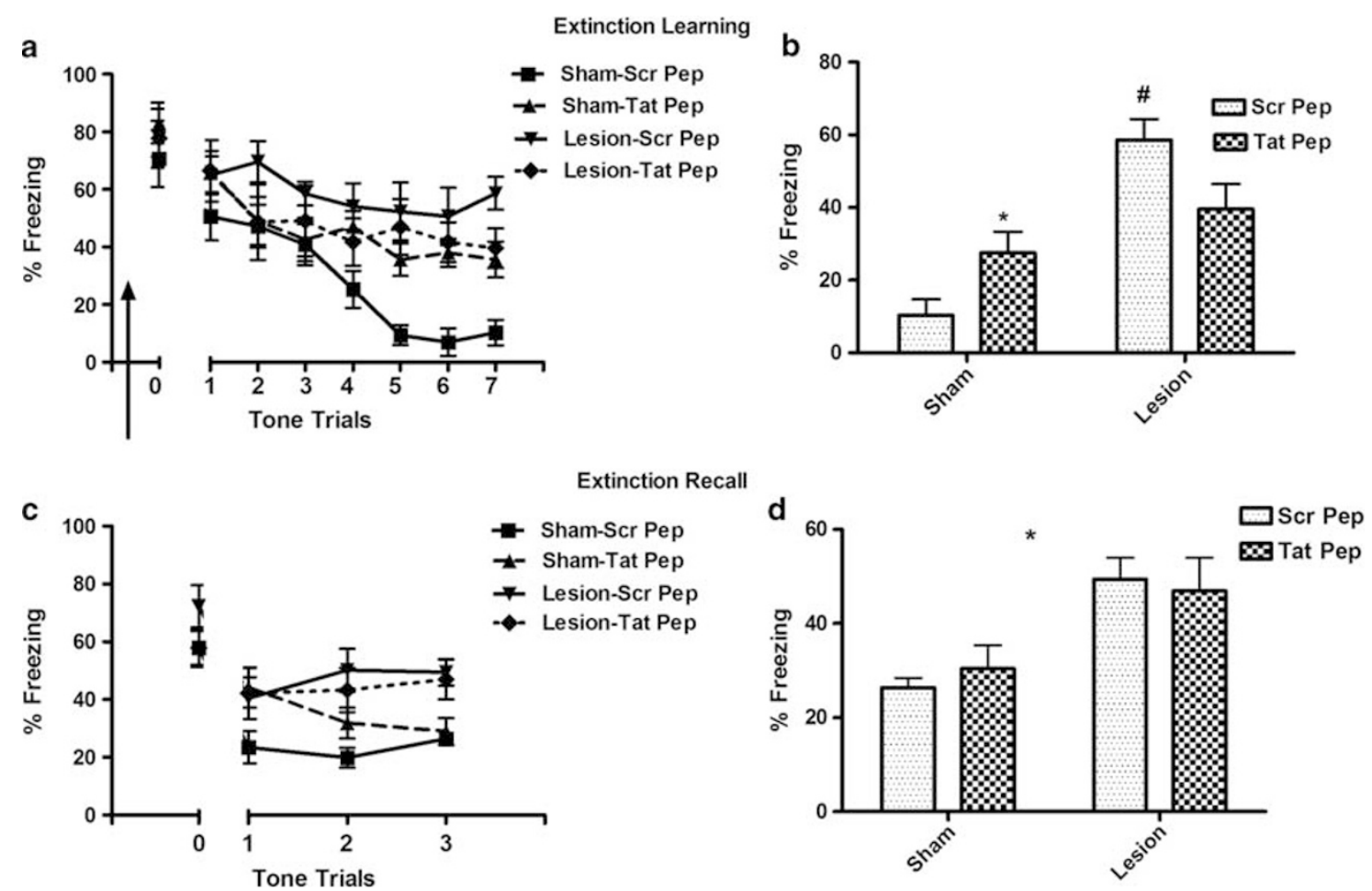

Figure 5 Effect of medial prefrontal cortex (mPFC) infusion of AMPA receptor endocytosis blocker Tat-GluR2 3 Y on extinction memory in sham and neonatal ventral hippocampus (nVH)-lesioned animals. (a) Extinction learning curve of rats infused with either scrambled peptide (Scr Pep, 15 pmoles) or Tat-GluR2 3 Y peptide (Tat-Pep, 15 pmoles) bilaterally into infralimbic PFC, 30 min before the session (arrow sign). (b) Bar diagram of mean ( \pm SEM) freezing response at the last block of two trials in the four groups of animals. Lesion-Scr Pep animals show increased freezing compared with sham-Scr Pep $\left({ }^{\#} p<0.00 \mathrm{I}\right)$ indicating resistance to extinction. Tat-GluR2 3 y peptide infusion caused increased freezing in sham animals $(* p=0.005 \mathrm{vs}$ sham-Scr Pep). However, the Tat-GluR2 ${ }_{3 y}$ peptide has no significant effect in lesioned animals. (c) Freezing responses of the animals during the extinction recall session. (d) Mean \pm SEM of freezing responses at the last block of two-tone trials during recall. Lesioned animals with scrambled peptide infusion show impaired recall memory compared with sham animals with scrambled peptide (*, main effect of lesion, $p=0.0002$ ). Tat-GluR2 $3 y$ peptide had no significant effect on extinction recall in sham or $\mathrm{nVH}$-lesioned animals.

decreased number of dendritic spines in MPFC pyramidal neurons in nVH-lesioned animals (Ryan et al, 2013), we asked whether mPFC neurons of lesioned animals show changes in $\alpha$-1AR-mediated plasticity of glutamate synapses. Our results suggest that the influence of $\alpha-1 \mathrm{AR}$ on the plasticity of glutamatergic transmission is markedly diminished in $\mathrm{nVH}$-lesioned rats. Incubation of PFC slices of sham-operated animals with NE led to an LTD of excitatory postsynaptic response of layer $\mathrm{V}$ pyramidal cells evoked by stimulating superficial layers of $\mathrm{MPFC}$, which can be blocked by an $\alpha-1 \mathrm{AR}$ antagonist prazosin. This form of $\alpha$-1-dependent NE-LTD ( $\alpha$-1AR-LTD) has been previously demonstrated in other brain regions as well (Kirkwood et al, 1999; Scheiderer et al, 2004; McElligott and Winder, 2008). Most interestingly, we found that the $\alpha$-1AR-LTD was completely absent in the mPFC of nVH-lesioned rats. This failure in LTD induction in the lesioned animals may be related to our finding of the failure of $\alpha-1 \mathrm{AR}$ to trigger downstream signaling such as ERK1/2. It is important to note that the short-term depression of EPSP superficial $_{\text {during }}$ and shortly after NE application was intact in slices from control and lesioned rats, suggesting that only LTD of EPSP $_{\text {superficial was affected. While NE-LTD is likely }}$ mediated by AMPAR endocytosis that is sensitive to TatGluR2 $2_{3 Y}$ peptide, mechanism underlying NE-induced shortterm depression seems to be related to $\alpha-2 \mathrm{AR}$ activation
(Marzo et al, 2010). These findings are consistent with our previous report showing selective changes in $\alpha-1 \mathrm{AR}$, but not $\alpha-2 \mathrm{AR}$ in $\mathrm{nVH}-\mathrm{lesioned}$ rats (Bhardwaj et al, 2004).

Our focus on fear memory extinction as a paradigm to assess cognitive correlate of abnormal $\alpha$-1AR signaling and plasticity was predicated on the reasoning that this behavior is associated with adrenergic transmission and long-term plasticity within the mPFC neurons (LeDoux, 2000; Quirk and Mueller, 2008; Mueller and Cahill, 2010). Further, while impaired fear extinction is common in conditions of altered adrenergic responsivity, such as post-traumatic stress disorder and stress (Holmes and Wellman, 2008), a deficit in fear extinction memory has also been shown in individuals suffering from schizophrenia (Holt et al, 2009). Fear extinction is widely believed to be a new form of learning, and is modulated by inputs from MPFC to the amygdala. Increased IL PFC neuronal activity is associated with retrieval of extinction memory (Milad and Quirk, 2002; Santini et al, 2008), and mPFC NE (Hugues et al, 2007) and activation of $\alpha-1$, as well as $\beta$-AR-associated PKA signaling in the IL PFC appear necessary for fear extinction (Mueller et al, 2008; Do-Monte et al, 2010).

Our data show that nVH-lesioned animals have significant impairments in learning to extinguish fear memory and consolidating extinction memory. These impairments are apparently not due to altered anxiety-like behaviors of 
lesioned animals, as previous studies have shown no significant change in anxiety-like behaviors (Wood et al, 2003). It may be argued that these deficits are due to altered functioning of amygdala or the hippocampus; however, due to normal expression of fear during conditioning or in the tests of contextual and auditory fear memory, it seems less likely. Further, adult hippocampus inactivation does not significantly affect acquisition of extinction (Corcoran et al, 2005).

We also find that, unlike in controls, mPFC infusion of $\alpha-1 \mathrm{AR}$ antagonist in $\mathrm{nVH}$-lesioned animals is without any significant effect, that is, the extinction learning and memory impairments are not exacerbated. We believe that impaired fear extinction in $\mathrm{nVH}$-lesioned animals is due to $\mathrm{mPFC} \alpha-1 \mathrm{AR}$ abnormality, as these receptors in $\mathrm{nVH}$ animals are non-responsive to agonist stimulation, and because $\alpha$-1AR-dependent LTD in MPFC circuit is unable to form.

LTD-related mechanisms have been reported to facilitate extinction and consolidation of extinction memory in rats. Systemic administration of Tat-GluR2 $2_{3 y}$ peptide that blocks AMPAR endocytosis, a key mechanism in LTD formation, interferes with learning of extinction as well as recall of fear memory (Dalton et al, 2008). Our data showing deficits in extinction learning and recall by $\mathrm{mPFC}$ microinfusion of Tat-GluR2 $2_{3 Y}$ peptide in sham animals suggest that LTD in the $\mathrm{mPFC}$ is necessary for normal extinction learning, but not for recall. Further, similar to the results with $\alpha-1 \mathrm{AR}$ antagonist benoxathian, mPFC microinfusion of TatGluR2 3 peptide in the lesioned animals did not exacerbate extinction learning or recall. This data, suggestive of mPFC LTD deficit in lesioned animals is consistent with our in vitro data showing a loss of $\alpha-1 \mathrm{AR}$-mediated LTD in layer $1 / 2 \rightarrow 5$ of the $\mathrm{mPFC}$.

Tat-GluR2 $2_{3 Y}$ peptide would also affect LTD that is induced by non-adrenergic stimuli, for example, glutamate NMDA receptor (Ge et al, 2010). However, similar effects of this peptide and $\alpha-1 \mathrm{AR}$ antagonist on fear extinction may suggest a common cellular mechanism targeted by these two distinct pharmacological reagents, that is, $\alpha-1$ AR-LTD in the mPFC. Previous studies suggest that extinction is associated with increased excitability of IL PFC excitatory neurons that project to amygdala to inhibit fear (Quirk and Beer, 2006). While it seems counterintuitive that LTD, which could reduce neuronal excitability, promotes fear extinction, it is important to note that only a subset of cortico-cortical inputs from the superficial layer I/II to layer $\mathrm{V}$ pyramidal neurons can be depressed by NE. Selective $\alpha-1$ adrenergic suppression of these inputs could reduce synaptic noises from intrinsic cortical network that could facilitate detection of stimuli from other cortical and more important extrinsic inputs that could influence layer $\mathrm{V}$ pyramidal neuronal excitability. This increase in signal/noise ratio mediated by $\alpha-1 \mathrm{AR}$ could have significant impact on enhancing extinction that requires detection of dissociation between salient cues and noxious stimuli. Diminution of this $\alpha-1 \mathrm{AR}$ function, we believe, may be responsible for extinction learning/memory deficit in $\mathrm{nVH}$-lesioned animals. At the same time, it is possible that other PFC abnormalities described in the nVH-lesioned animals may also be involved in extinction deficits in these animals. In particular, mPFC GABAergic interneuron deficit described in the lesioned animals (Tseng et al, 2008) could contribute to extinction deficits by altering excitability of the mPFC pyramidal cells. It has been shown that GABA-A receptor agonist muscimol infusion in the IL PFC before extinction training results in long-term facilitation of extinction (Akirav et al, 2006). Further, extinction of reward-seeking behavior, which shares PFC neural circuits with fear extinction (Peters et al, 2009), was recently shown to be facilitated by optogenetic stimulation of fast spiking parvalbumin interneurons in the PL MPFC of mice (Sparta et al, 2014).

$\mathrm{NE}$ is increasingly being recognized as an important modulator of prefrontal cognitive functions, impairments in which is a hallmark of schizophrenia and other psychiatric disorders (Arnsten, 2011). Whereas excessive $\alpha-1$ activation impairs working memory functions (Arnsten et al, 1999; Arnsten, 2000), noradrenergic activity at mPFC $\alpha 1$-receptors facilitates attentional and cognitive performance of rats, for example, behavioral flexibility (Sirvio and MacDonald, 1999; Lapiz and Morilak, 2006). Our present set of data linking impaired $\alpha-1$ adrenergic regulation of cortical glutamatergic synaptic plasticity and cognition in $\mathrm{nVH}$ lesion model may represent novel mechanisms of prefrontal dysfunctions observed in neurodevelopmental mental disorders.

\section{FUNDING AND DISCLOSURE}

This study was supported by a grant from the Canadian Institutes of Health Research (MOP-68922). The authors declare no conflict of interest.

\section{REFERENCES}

Ahmadian G, Ju W, Liu L, Wyszynski M, Lee SH, Dunah AW et al (2004). Tyrosine phosphorylation of GluR2 is required for insulin-stimulated AMPA receptor endocytosis and LTD EMBO J 23: 1040-1050.

Akirav I, Raizel H, Maroun M (2006). Enhancement of conditioned fear extinction by infusion of the GABAA agonist muscimol into the rat prefrontal cortex and amygdala. Eur J Neurosci 23: 758-764.

Al-Khairi I, Baharnoori M, Kamath A, Bhardwaj SK, Srivastava LK (2009). Altered expression and alpha-1 adrenergic receptor mediated activity of protein kinase $\mathrm{C}$ in the prefrontal cortex of rats with neonatal ventral hippocampus lesions. Synapse 63: 1051-1059.

Arnsten AF (2000). Stress impairs prefrontal cortical function in rats and monkeys: role of dopamine D1 and norepinephrine alpha-1 receptor mechanisms. Prog Brain Res 126: 183-192.

Arnsten AF (2011). Catecholamine influences on dorsolateral prefrontal cortical networks. Biol Psychiatry 69: e89-e99.

Arnsten AF, Mathew R, Ubriani R, Taylor JR, Li BM (1999). Alpha1 noradrenergic receptor stimulation impairs prefrontal cortical cognitive function. Biol Psychiatry 45: 26-31.

Aston-Jones G, Rajkowski J, Cohen J (2000). Locus coeruleus and regulation of behavioral flexibility and attention. Prog Brain Res 126: $165-182$.

Bagot RC, Tse YC, Nguyen HB, Wong AS, Meaney MJ, Wong TP (2012). Maternal care influences hippocampal N-methyl-Daspartate receptor function and dynamic regulation by corticosterone in adulthood. Biol Psychiatry 72: 491-498.

Berridge CW, Waterhouse BD (2003). The locus coeruleusnoradrenergic system: modulation of behavioral state and 
state-dependent cognitive processes. Brain Res Brain Res Rev 42: 33-84.

Bhardwaj SK, Baharnoori M, Sharif-Askari B, Kamath A, Williams S, Srivastava LK (2009). Behavioral characterization of dysbindin-1 deficient sandy mice. Behav Brain Res 197: 435-441.

Bhardwaj SK, Quirion R, Srivastava LK (2004). Post-pubertal adrenergic changes in rats with neonatal lesions of the ventral hippocampus. Neuropharmacology 46: 85-94.

Brebner K, Wong TP, Liu L, Liu Y, Campsall P, Gray S et al (2005). Nucleus accumbens long-term depression and the expression of behavioral sensitization. Science 310: 1340-1343.

Carr DB, Sesack SR (1996). Hippocampal afferents to the rat prefrontal cortex: synaptic targets and relation to dopamine terminals. J Comp Neurol 369: 1-15.

Collingridge GL, Peineau S, Howland JG, Wang YT (2010). Longterm depression in the CNS. Nat Rev Neurosci 11: 459-473.

Corcoran KA, Desmond TJ, Frey KA, Maren S (2005). Hippocampal inactivation disrupts the acquisition and contextual encoding of fear extinction. J Neurosci 25: 8978-8987.

Dalton GL, Wang YT, Floresco SB, Phillips AG (2008). Disruption of AMPA receptor endocytosis impairs the extinction, but not acquisition of learned fear. Neuropsychopharmacology 33: 2416-2426.

Do-Monte FH, Allensworth M, Carobrez AP (2010). Impairment of contextual conditioned fear extinction after microinjection of alpha-1-adrenergic blocker prazosin into the medial prefrontal cortex. Behav Brain Res 211: 89-95.

Flores G, Alquicer G, Silva-Gomez AB, Zaldivar G, Stewart J, Quirion R et al (2005). Alterations in dendritic morphology of prefrontal cortical and nucleus accumbens neurons in postpubertal rats after neonatal excitotoxic lesions of the ventral hippocampus. Neuroscience 133: 463-470.

Flores G, Barbeau D, Quirion R, Srivastava LK (1996). Decreased binding of dopamine D3 receptors in limbic subregions after neonatal bilateral lesion of rat hippocampus. J Neurosci 16: 2020-2026.

Gamo NJ, Arnsten AF (2011). Molecular modulation of prefrontal cortex: rational development of treatments for psychiatric disorders. Behav Neurosci 125: 282-296.

Ge Y, Dong Z, Bagot RC, Howland JG, Phillips AG, Wong TP et al (2010). Hippocampal long-term depression is required for the consolidation of spatial memory. Proc Natl Acad Sci USA 107: 16697-16702.

Gruber AJ, Calhoon GG, Shusterman I, Schoenbaum G, Roesch MR, O'Donnell P (2010). More is less: a disinhibited prefrontal cortex impairs cognitive flexibility. J Neurosci 30: 17102-17110.

Holmes A, Wellman CL (2008). Stress-induced prefrontal reorganization and executive dysfunction in rodents. Neurosci Biobehav Rev 33: 773-783.

Holt DJ, Lebron-Milad K, Milad MR, Rauch SL, Pitman RK, Orr SP et al (2009). Extinction memory is impaired in schizophrenia. Biol Psychiatry 65: 455-463.

Hugues S, Garcia R, Lena I (2007). Time course of extracellular catecholamine and glutamate levels in the rat medial prefrontal cortex during and after extinction of conditioned fear. Synapse 61: 933-937.

Kamath A, Al-Khairi I, Bhardwaj S, Srivastava LK (2008). Enhanced alphal adrenergic sensitivity in sensorimotor gating deficits in neonatal ventral hippocampus-lesioned rats. Int $J$ Neuropsychopharmacol 11: 1085-1096.

Kirkwood A, Rozas C, Kirkwood J, Perez F, Bear MF (1999). Modulation of long-term synaptic depression in visual cortex by acetylcholine and norepinephrine. J Neurosci 19: 1599-1609.

Koshimizu TA, Tanoue A, Hirasawa A, Yamauchi J, Tsujimoto G (2003). Recent advances in alphal-adrenoceptor pharmacology. Pharmacol Ther 98: 235-244.

Lapiz MDS, Morilak DA (2006). Noradrenergic modulation of cognitive function in rat medial prefrontal cortex as measured by attentional set shifting capability. Neuroscience 137: 1039-1049.

LeDoux JE (2000). Emotion circuits in the brain. Annu Rev Neurosci 23: 155-184.

Marcotte ER, Pearson DM, Srivastava LK (2001). Animal models of schizophrenia: a critical review. J Psychiatry Neurosci 26: 395-410.

Marquis JP, Goulet S, Dore FY (2008). Neonatal ventral hippocampus lesions disrupt extra-dimensional shift and alter dendritic spine density in the medial prefrontal cortex of juvenile rats. Neurobiol Learn Mem 90: 339-346.

Marzo A, Bai J, Caboche J, Vanhoutte P, Otani S (2010). Cellular mechanisms of long-term depression induced by noradrenaline in rat prefrontal neurons. Neuroscience 169: 74-86.

McElligott ZA, Winder DG (2008). Alpha1-adrenergic receptorinduced heterosynaptic long-term depression in the bed nucleus of the stria terminalis is disrupted in mouse models of affective disorders. Neuropsychopharmacology 33: 2313-2323.

Milad MR, Quirk GJ (2002). Neurons in medial prefrontal cortex signal memory for fear extinction. Nature 420: 70-74.

Mueller D, Cahill SP (2010). Noradrenergic modulation of extinction learning and exposure therapy. Behav Brain Res 208: 1-11.

Mueller D, Porter JT, Quirk GJ (2008). Noradrenergic signaling in infralimbic cortex increases cell excitability and strengthens memory for fear extinction. J Neurosci 28: 369-375.

Nicholls RE, Alarcon JM, Malleret G, Carroll RC, Grody M, Vronskaya S et al (2008). Transgenic mice lacking NMDARdependent LTD exhibit deficits in behavioral flexibility. Neuron 58: 104-117.

Nicniocaill B, Gratton A (2007). Medial prefrontal cortical alpha1 adrenoreceptor modulation of the nucleus accumbens dopamine response to stress in Long-Evans rats. Psychopharmacology (Berl) 191: 835-842.

O’Donnell P, Lewis BL, Weinberger DR, Lipska BK (2002). Neonatal hippocampal damage alters electrophysiological properties of prefrontal cortical neurons in adult rats. Cereb Cortex 12: 975-982.

Paxinos G, Watson C (2007). The Rat Brain in Stereotaxic Coordinates. Academic Press: New York, USA.

Peters J, Kalivas PW, Quirk GJ (2009). Extinction circuits for fear and addiction overlap in prefrontal cortex. Learn Mem 16: 279-288.

Quirk GJ, Beer JS (2006). Prefrontal involvement in the regulation of emotion: convergence of rat and human studies. Curr Opin Neurobiol 16: 723-727.

Quirk GJ, Mueller D (2008). Neural mechanisms of extinction learning and retrieval. Neuropsychopharmacology 33: 56-72.

Ramos BP, Arnsten AF (2007). Adrenergic pharmacology and cognition: focus on the prefrontal cortex. Pharmacol Ther 113: 523-536.

Ryan RT, Bhardwaj SK, Tse YC, Srivastava LK, Wong TP (2013). Opposing alterations in excitation and inhibition of layer 5 medial prefrontal cortex pyramidal neurons following neonatal ventral hippocampal lesion. Cereb Cortex 23: 1198-1207.

Santini E, Quirk GJ, Porter JT (2008). Fear conditioning and extinction differentially modify the intrinsic excitability of infralimbic neurons. J Neurosci 28: 4028-4036.

Scheiderer CL, Dobrunz LE, McMahon LL (2004). Novel form of long-term synaptic depression in rat hippocampus induced by activation of alpha 1 adrenergic receptors. J Neurophysiol 91: 1071-1077.

Sirvio J, MacDonald E (1999). Central alpha1-adrenoceptors: their role in the modulation of attention and memory formation. Pharmacol Ther 83: 49-65.

Sparta DR, Hovelso N, Mason AO, Kantak PA, Ung RL, Decot HK et al (2014). Activation of prefrontal cortical parvalbumin interneurons facilitates extinction of reward-seeking behavior. J Neurosci 34: 3699-3705. 
Thierry AM, Gioanni Y, Degenetais E, Glowinski J (2000). Hippocampo-prefrontal cortex pathway: Anatomical and electrophysiological characteristics. Hippocampus 10: 411-419.

Thomson AM, Deuchars J (1997). Synaptic interactions in neocortical local circuits: dual intracellular recordings in vitro. Cereb Cortex 7: 510-522.

Tseng KY, Chambers RA, Lipska BK (2009). The neonatal ventral hippocampal lesion as a heuristic neurodevelopmental model of schizophrenia. Behav Brain Res 204: 295-305.

Tseng KY, Lewis BL, Hashimoto T, Sesack SR, Kloc M, Lewis DA et al (2008). A neonatal ventral hippocampal lesion causes functional deficits in adult prefrontal cortical interneurons. J Neurosci 28: 12691-12699.

Van den Oever MC, Goriounova NA, Li KW, Van der Schors RC, Binnekade R, Schoffelmeer AN et al (2008). Prefrontal cortex AMPA receptor plasticity is crucial for cue-induced relapse to heroin-seeking. Nat Neurosci 11: 1053-1058.

Volk DW, Lewis DA (2010). Prefrontal cortical circuits in schizophrenia. Curr Top Behav Neurosci 4: 485-508.

Wood GK, Quirion R, Srivastava LK (2003). Early environment contributes to developmental disruption of MPFC after neonatal ventral hippocampal lesions in rats. Synapse 50: 223-232.

Supplementary Information accompanies the paper on the Neuropsychopharmacology website (http://www.nature.com/npp) 